\section{HELICOBACTER PYLORI E DOENÇA PÉPTICA - 25 ANOS DE HISTÓRIA}

A comunidade científica celebra este ano o $25^{\circ}$ aniversário da publicação do estudo de Marshall e Warren sobre o Helicobacter pylori. Este estudo é um marco importante da gastroenterologia, uma vez que identifica a bactéria e estabelece os alicerces para a compreensão da fisiopatogenia do H. Pylori e da doença péptica.

Os pesquisadores australianos publicaram os seus achados na Lancet, uma revista de renome internacional e de grande impacto no meio científico. O estudo analisa 100 pacientes consecutivos submetidos à gastroscopia para elucidação de queixas digestivas. Os objetivos foram: confirmar a associação entre a presença de bactéria e o quadro de gastrite antral, descobrir fatores predisponentes de infecção pela bactéria, descobrir doenças gastrointestinais associadas e identificar a bactéria por meio de culturas. Os autores identificaram um bacilo curvado ou espiralado em amostras de biópsia gástrica de 58 pacientes. A cultura se mostrou positiva em 11 pacientes e demonstrou bactéria Gram negativa, flagelada, microaerofílica e semelhante às bactérias do gênero Campylobacter. A bactéria esteve presente em todas as amostras de pacientes com úlcera duodenal. Não se conseguiu uma associação positiva com fatores predisponentes.

$O$ estudo foi conduzido em uma era anterior ao advento dos inibidores de bomba protônica, na qual o arsenal terapêutico para doença péptica incluía os antiácidos e bloqueadores H2. Este estudo representa uma ruptura no modelo dicotômico de classificação de doenças (infecciosas x não-infecciosas), passando a se entender que a doença péptica não advém somente de estados de hiperacidez, mas está intimamente associado a uma bactéria causadora. Havia outros relatos da existência de bactéria associada à gênese da gastrite, no entanto não havia sido estabelecido um nexo causal entre a sua presença e doenças pépticas. Os autores associaram a presença de infiltrado linfoplasmocitário à gastrite e conseguiram o isolamento da bactéria a partir da cultura de fragmentos de biópsia gástrica.

Hoje a evolução natural da gastrite crônica pelo $H$. Pylori já está bem estabelecida. Sabe-se que a gastrite inicialmente assume um aspecto superficial, passando pela gastrite atrófica e progredindo até atrofia gástrica ou metaplasia intestinal gástrica. A bactéria também é implicada como fator de risco para câncer gástrico e linfoma Malt. Hoje são conhecidos os fatores de agressão do patógeno e já existem preocupações com o perfil de sensibilidade e resistência da bactéria aos antibióticos habitualmente utilizados. Tendo em vista tudo o que foi exposto, pode-se posicionar este trabalho como a mais importante publicação da gastroenterologia do século $\mathrm{XX}$, pois revolucionou o tratamento e abordagem clínica da doença ulcerosa péptica, diminuindo a frequência do tratamento cirúrgico e possibilitando o desenvolvimento de outras pesquisas.

Gustavo Pignaton de Freitas Rio de Janeiro, RJ

Referência

1. Marshall BJ, Warren JR. Unidentified curved bacilli in the stomach of patients with gastritis and peptic ulceration. Lancet. 1984;1(8390): 1311-5. 